\title{
Medication adherence and Its Correlates among Diabetic Patients in Central Hospital, warri, nigeria
}

\author{
Aghoja $\mathrm{OC}^{1}$, Avwenaghagha $\mathrm{HO}^{1}$, Ogba $\mathrm{ER}^{2}$, \\ 1 Department of Clinical Pharmacy and pharmacy Administration, Faculty of Pharmacy, Delta State University \\ Abraka, Delta State, Nigeria. \\ 2 Lifehealth global pharmacy and stores limited, 37 bazunu road, Warri, Delta State Nigeria
}

\begin{abstract}
INTRODUCTION: Adhering to medication in the course of the treatment of diabetes requires significant patient involvement to maintain appropriate glucose control. Glucose control is directly related to adherence to a variety of treatment regimes, of which medication adherence is one of the most significant, lack of knowledge about the complications of the disease following non adherence and the importance of adhering to the prescribed medication is a barrier to adherence behavior.

OBJECTIVES: The objectives of this study were to determine the level of adherence with medications by respondents and to ascertain the reasons for non-adherence.

METHODS: A quantitative prospective survey of 300 diabetic patients that attended the Medical Outpatient Department of Central Hospital Warri was undertaken.

RESULTS: The study revealed that the level of adherence to anti-diabetic medications was 59.7\%. The major reasons for non-adherence were forgetfulness by the respondents to take their medications and high cost of medications.
\end{abstract}

CONCLUSION: The level of adherence among diabetic patients in this study was 59.7\% thus indicating the need for patients counseling and education.

KEYWORDS: Adherence, diabetes, hospital medication, patients.

\section{INTRODUCTION}

Diabetes mellitus is a group of diseases characterized by high levels of blood glucose resulting from defects in insulin secretion, insulin action or a combination of both conditions [1].The prevalence diabetes is high, afflicting approximately 150 million people worldwide, and is expected to increase to 300 million in the year 2025 [2,3]. It has been reported that much of this increase will occur in developing countries including Nigeria, as a result of ageing, unhealthy diet, obesity and sedentary lifestyle [3]. Contemporary perspectives on diabetes care accord a central role to patients' self-care. Self-care implies basically that the patient actively monitors and responds to changing environment and biological conditions by making adaptive adjustments in the different aspects of diabetes treatment in order to maintain adequate metabolic control and reduce the probability of complications [4].

Self-care behaviors involved in achieving adequate metabolic control and avoiding long-term complications include home glucose monitoring; adjustment of food intake, especially of carbohydrates, to meet daily needs and match available insulin [5]. The goals of diabetes treatment are to keep blood glucose levels as normal as possible while avoiding acute and chronic complications [6]. For these goals to be achieved patients on therapy and lifestyle modifications must take their drugs as prescribed by physicians. However, no matter how appropriate and effective anti-diabetic therapy may be, there will be poor clinical outcomes when the level of adherence to medication is poor. Adherence to prescribed medication is key to achieving desired clinical outcome. According to the World Health Organization, (WHO), adherence is the extent to which a person's behavior-taking medication, following a diet, and/or executing lifestyle changes-corresponds with agreed recommendations from the health care provide [7] However, medication non-adherence is particularly common among patients with type 2 diabetes [8] and inadequate adherence compromises the patient's safety and treatment effectiveness, leading to increased mortality and morbidity with considerable effect on the direct and indirect effect on costs to the healthcare system [9]. A recent report by WHO has stated that the magnitude of non-adherence and the scope of its sequalae are so alarming, and that more health benefits worldwide would result from improving adherence to existing treatments than by developing new medical treatments [7]. A group of researchers have reported that lower fasting blood glucose levels are associated with reduced mortality and incidence of complications in patients with type 2 diabetes. [10]. However, ensuring that patients take oral hypoglycaemic medications as prescribed and therefore achieving normal or near normal blood glucose control constitute the most common challenges encountered by physicians and other health care providers involved in 
the treatment of patients with diabetes[11]. There is need to address all phases of diabetes treatment which makes it imperative to understand the factors affecting patient's adherence to medications in order to identify the areas upon which counseling should be focused as well as assisting in the development of future interventions to improve adherence and treatment outcomes of diabetes.

The term adherence is intended to be nonjudgmental - a statement of fact rather than of blame of the individual, the prescriber, or the treatment. Compliance and concordance are synonyms for adherence. Adherence to treatment is a complex health behavior. Non-adherence to treatment is a formidable problem, as it often leads to a reduction in or lack of treatment benefits, extra visits to the doctor, unnecessary hospitalization, decreased satisfaction with medical care and sometimes further medication prescription. This can be extremely costly, not only to the individuals involved, but also to the healthcare system as a whole.

Therefore there is a continuing need to routinely assess the likely reasons for non-adherence among patients with diabetes in clinical practice. This is especially important in developing countries such as Nigeria where economic instability and inadequate access to health care facilities might have led to the increased incidence of medication non-adherence. Adherence to long-term therapy for chronic illnesses in developed countries averages 50\% [7]. In developing countries, the rates are even lower. It is undeniable that many patients experience difficulty in adhering to treatment recommendations. Poor adherence to long-term therapies severely compromises the effectiveness of treatment making this a critical issue in population health both from the perspective of quality of life and cost of health. While studies have been conducted universally on the subject, specific studies to evaluate the level of adherence as well as reasons for non adherence in Warri are lacking. To the researcher's knowledge, no such study had been undertaken in Warri. The goal of this study is to determine the level of adherence to medications among diabetic patients and to ascertain the reasons for non adherence.

\section{METHODS}

\subsection{Study design}

This study was a quantitative prospective survey of adult patients attending the Medical Outpatient Department of Central Hospital Warri over a period of three months.

\subsection{Settings and study population}

Central hospital Warri is a secondary healthcare institution located in Warri South local government area of Delta State. It has the highest Patients' output in the Delta state compared to other secondary healthcare institutions. There are different ethnic groups in Warri, but predominantly are the Urhobos, ijaws, isokos and Itsekiris. The hospital is a 252-bed facility that cares for both inpatients and outpatients. The wards are situated at various locations within the hospital and consist of the Male Medical Ward, Male surgical Ward, Female Medical Ward, Female surgical ward, Accident and Emergency Ward, Obstetrics and Gynaecology Ward, Pediatric Ward, and Psychiatric Ward. There is also a Pharmacy department, and a laboratory. It also has a heart to heart center. The hospital is a teaching facility for medical students, pharmacy interns, house officer, medical laboratory scientists and physiotherapy interns.

The hospital has a Pharmacy department which has a total of sixteen pharmacists of which eight are intern pharmacists and a corper pharmacist during the time of the study.

There are 52 medical practitioners in the hospital; this includes 10 consultants, 2 senior registrars and 32 others.

\subsection{Case selection}

\subsubsection{Inclusion criteria}

Patients aged 18 years and above with diabetes mellitus and have been on anti diabetic medications and who gave their consent to participate in the study.

\subsubsection{Exclusion criteria}

Patients who were too ill, patients who did not give their consent and mentally deranged patients.

\subsection{Sample size and sampling technique}

A sample size of 157 was obtained using an appropriate statistical formula for estimating minimum sample size in health studies [12] using a prevalence rate of $11 \%$ as found in a study on the profile of Nigerians with diabetes mellitus [13]). Patients that met the inclusion criteria were consecutively recruited until the required sample size was obtained.

The minimum sample size is therefore 157. The sample was made up to 300 to allow for incomplete or missing data. 


\subsection{Tool for data collection and technique}

Data collection was done using the Morisky-8 Items questionnaire. The questionnaire consisted of three sections. Section A comprised of patients demographic data. Section B comprised questions on medication adherence and Section $\mathrm{C}$ comprise of question on reasons for non adherence.

\subsection{Ethical consideration}

Ethical clearance was obtained from the ethics committee of the hospital prior to commencement of the study. Relevant guidelines for maintaining confidentiality of information were adhered to.

\subsection{Data management an statistical analysis}

The data collected was coded as per variables and entered in statistical package for the social sciences (SPSS) data sheet. SPSS statistical software (SPSS for windows version 16.0) was used for analysis. Association between socio-demographic variables and adherence were explored using the Chi-square test.

\section{RESULTS}

The socio-demographic characteristics of the respondents are shown in Table 1. Out of the 300 patients selected in line with the set criteria, $55.7 \%$ were female while $44.3 \%$ were male $39.7 \%$ of the respondents were 65 years and above, $32.3 \%$ were between the ages of 55 and $64,21.3 \%$ were between the ages of $45-64$ and a few $6.7 \%$ were below 45 years old. Majority of the respondents were married (71.2\%), and others were single at the time of the study Majority of the respondents had tertiary education (36.7\%), 28.3\% had secondary education, $25.3 \%$ had primary education while $9.7 \%$ had no education. Also, $33.3 \%$ were self employed, $29 \%$ were employed, $24.7 \%$ were unemployed while $13 \%$ were retired.

Figure 1 shows that the major reasons respondents did not adhere to their medication is forgetfulness.

Table 1: Socio Demographic Characteristics of Respondents

\begin{tabular}{l|r|r}
\hline Characteristics & Frequency & percent \\
\hline Age & 0 & 0 \\
$18-24$ & 0 & 0 \\
$25-34$ & 20 & 6.7 \\
$35-44$ & 64 & 21.3 \\
$45-54$ & 97 & 32.3 \\
$55-64$ & 119 & 39.7 \\
65 years \& above & & \\
Sex & 133 & 44.3 \\
MALE & 167 & 55.7 \\
FEMALE & & \\
& & \\
Marital Status & 202 & 1.7 \\
MARRIED & 5 & 3,3 \\
SINGLE & 10 & 4.0 \\
SAPARATED & 12 & 23.7 \\
DIVORCED & 71 & \\
WIDOWED & & 9.7 \\
& & 25.3 \\
Educational Status & 29 & 28.3 \\
NONE & 76 & 36.7 \\
PRIMARY & 85 & \\
SECONDARY & 110 & 29.0 \\
TERTIARY & & 33.3 \\
& & 24.7 \\
Occupation & 87 & 13.0 \\
EMPLOYED & 100 & 100 \\
SELF-EMPLOYED & 74 & \\
UNEMPLOYED & 39 & \\
RETIRED & 300 & \\
\hline TOTAL & & \\
& & \\
& &
\end{tabular}


Table 2: Data of Self Reported Level of Adherence to Medication

Table 2 shows that $59.7 \%$ of the respondents were adherent to their medication, $35 \%$ were non-adherent to their medication, interestingly, $5.3 \%$ did not respond.

\begin{tabular}{lcc}
\hline Level of Adherence & Frequency & Percent \\
\hline Non-adherence & 105 & 35.0 \\
Adherence & 179 & 59.7 \\
No response & 16 & 5.3 \\
\hline Total & $\mathbf{3 0 0}$ & $\mathbf{1 0 0}$ \\
\hline
\end{tabular}

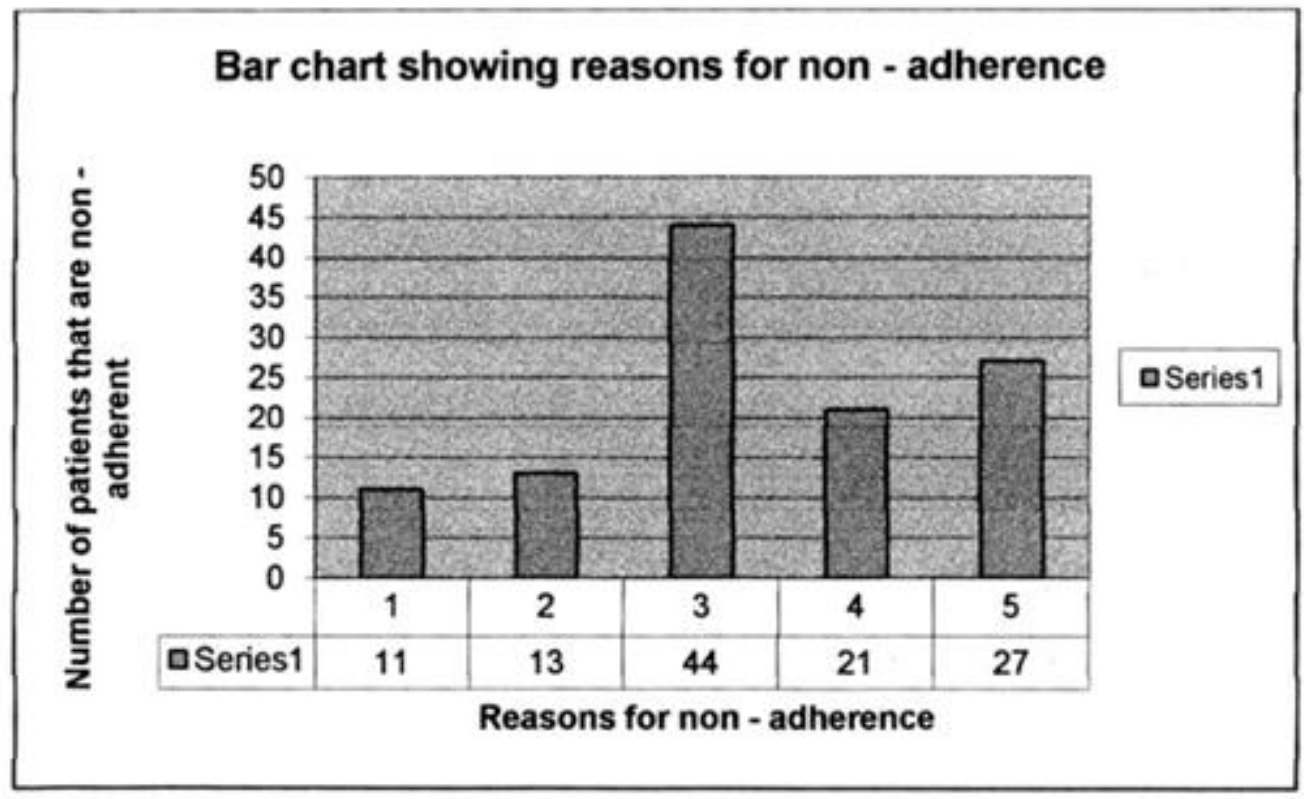

Fig 1: Bar Chart showing reasons for respondent non adherence against number of patients that were not adherent.N.B: Some respondents had more than one reason for not adhering to medications

Association between sociodemographic characteristics and adherence to treatment.

Factors found to be significantly associated with adherence on Chi square test were age (Cal. $\mathrm{X}^{2}=13.981$; $\mathrm{P}<0.01)$ and marital status $\left(\mathrm{Cal} . \mathrm{X}^{2}=13.897 ; \mathrm{P}<0.01\right)$. Gender $\left(\mathrm{Cal} . \mathrm{X}^{2}=0.186 ; \mathrm{P}>0.05\right)$, educational qualification $\left(\right.$ Cal. $\left.\mathrm{X}^{2}=6.047 ; \mathrm{P}>0.01\right)$ and occupation $\left(\mathrm{Cal} . \mathrm{X}^{2}=4.439 ; \mathrm{P}>0.01\right)$ were not considered significantly associated with patients adherence to treatment. 
Table 3 shows the results of the CHI square test.

\begin{tabular}{|c|c|c|c|c|c|}
\hline 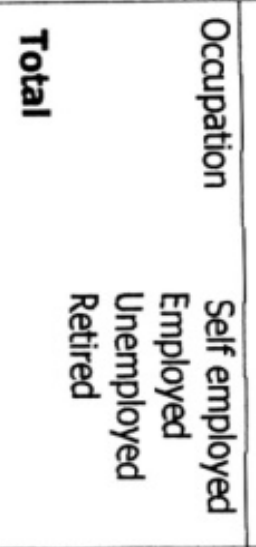 & 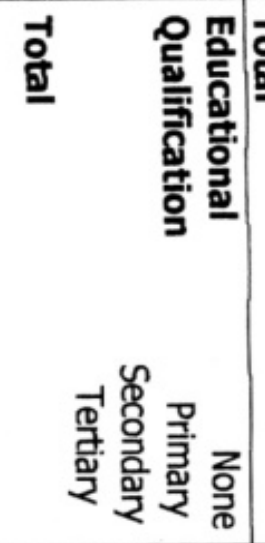 & 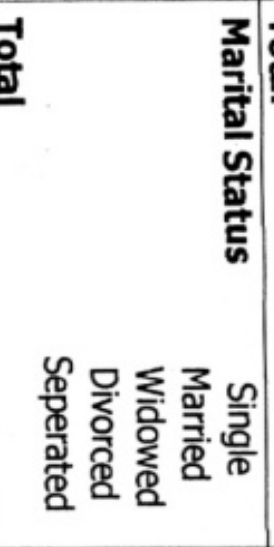 & 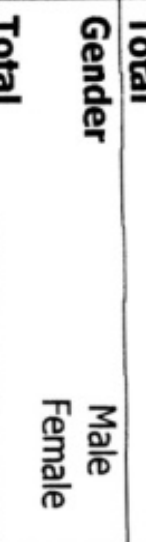 & 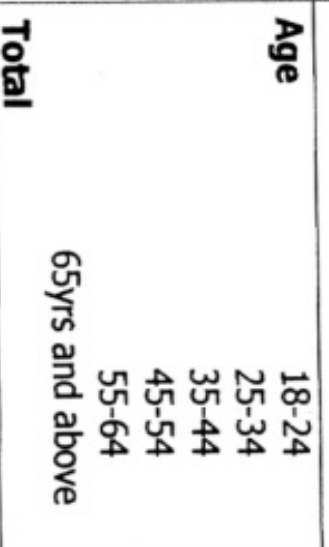 & 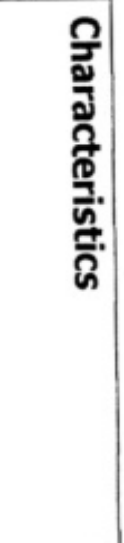 \\
\hline 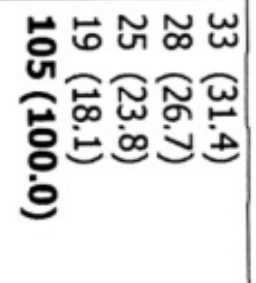 & 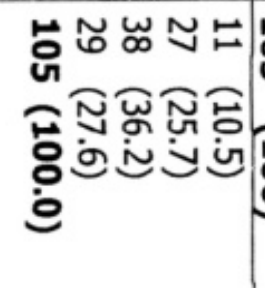 & 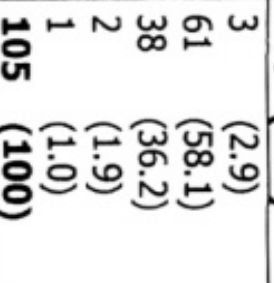 & 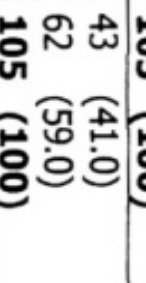 & 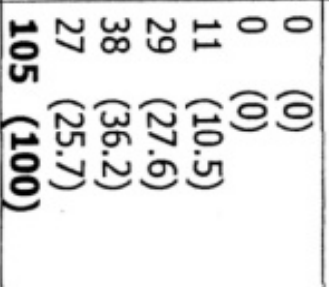 & 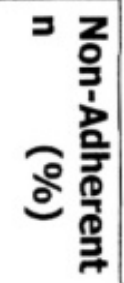 \\
\hline 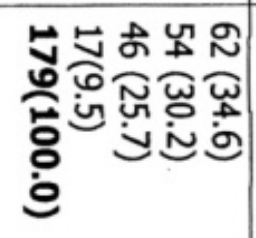 & 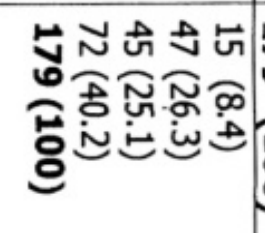 & 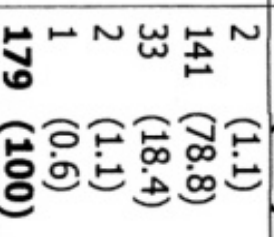 & 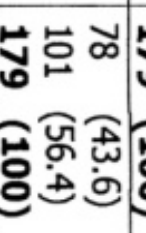 & 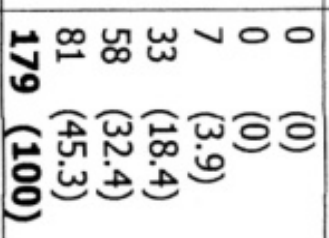 & 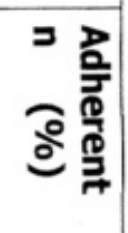 \\
\hline$\vec{\infty}$ & $\underset{\square}{u}$ & 点 & 인 & $\underset{\hookrightarrow}{\breve{\rightarrow}}$ & 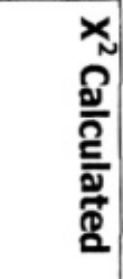 \\
\hline 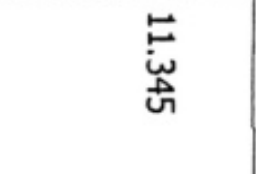 & $\underset{⿱ 乛}{\vec{w}}$ & $\underset{\tilde{\tilde{N}}}{\breve{v}}$ & $\begin{array}{l}\text { के } \\
\text { के }\end{array}$ & $\vec{v}$ & 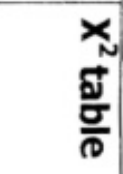 \\
\hline$\omega$ & $\omega$ & $\rightarrow$ & $\mapsto$ & u & 윽 \\
\hline
\end{tabular}

IV. 
In this study, more than half of the respondents were females. This is in line with studies carried out in other parts of the country such as Borno [14] and Ibadan [15]. This may be due to the fact that females visit the hospital more frequently during their reproductive years (antenatal care) whereby they were exposed to different medical test, examination and counseling on various health issues including diabetes. As soon as they perceive medical ailment, they tend to seek medical attention from healthcare providers. Majority of the respondents were in the age range of 45 years and above. This finding is in line with that carried out in Sagamu [16]. This shows that increasing age is a risk factor for diabetes mellitus. A large number of the respondents were married. Marriage provides a positive social environment that promotes adherences as spouse can support by way of reminders. This is important since the majority of the respondents attributed their non-adherence to medication to forgetfulness. It was also observed that majority of the respondents had formal education and were literate. A literate population is associated with better understanding of medication regimen leading to higher rate of adherence. The population studied was mainly literate and are capable of understanding the importance of medication adherence. Hence this may have contributed to reduced number of respondents that were nonadherent due to lack of understanding of medication regimen.

A large number of the respondents were either employed or self employed. This may contribute to non - adherence as a result of busy schedule of job which may lead to skipping of medication as well as contributing to forgetfulness which is a major reason for non adherence.

The level of adherence to medication regimen was relatively high. This is in agreement with the findings in a study carried out in Borno which reported a high level of adherence [14].

There are several factors that affect non-adherence with medication regimen. These can be classified into busy nature of work, forgetfulness, side effect of medication, cost of medication and stopping medication when feeling better. In this study these factors were used to evaluate non-adherence. The major reason why the respondents did not adhere with their medication regimen is forgetfulness. This is consistent with the findings in Ibadan Southern Nigeria which concluded that non adherence among respondents occurs mostly because of forgetfulness [15]. Forgetfulness is a widely reported factor that causes non-adherence with medication or clinic appointments. [17,18].

Another reason why respondents did not adhere with their medication is as a result of the high cost of medication. Some studies reported that high cost of prescribed anti-diabetic medications were mentioned by majority of the participants as part of the difficulties encountered during filling and refilling of prescriptions, and attributed their irregular purchase of their drug to this reason[19]. Cost is a crucial issue in patient's adherence to medication especially for patients with chronic disease as the treatment period is lifelong [20].

A number of respondents also attributed their not adhering to medication regimen to the side effect of medications. Some studies identified side effects among others as one of the causes of non adherence to antidiabetic medications [21]. The effect of side effects on adherence may be explained in terms of physical discomfort, skepticism about the efficacy of the medications.

There was no significant association between age and level of adherence. This is consistent with the findings reported in Borno [14] Most of the female respondents were adherent to their medication and there was no significant association between gender and level of adherence. This is inconsistent with a finding in Borno [14]. Majority of the respondent that were employed were adherent to their medication. However there was no significant association between occupation and level of adherence. There was a significant association between marital status and adherence. Marital status might influence patients' adherence with medications positively [22]. The help and support from a spouse could be the reason why married patients were more adherent with medication regimen than single patients .On the basis of educational qualification, there was no significant association between the level of education and adherence. This is consistent with the findings of some studies which reported same [23, 24].

\section{CONCLUSION}

In this study, the level of adherence to anti-diabetic medication regimen was relatively high (59.7Forgetfulness and affordability of prescribed medication are the major causes of patients non-adherence to their anti diabetic medication regimen in this study.

\subsection{The study limitations}

Some of the limitations are worth mentioning including the inability to determine the health insurance status of the participants. Also the use of self-reporting questionnaires which only rely on the honesty of those reporting them may not adequately reflect the complex aspects of the medication taking behaviour. 


\section{RECOMMENDATION}

1. The physicians and pharmacists should improve on the area of patient education and medication counseling, communication between them and patients, medication selection bearing in mind cost and intolerable side effects of the medications.

2. Physicians and Pharmacists should also adopt interventions that are designed to help patients remember to keep their clinic appointments and to take their anti-diabetic medications as prescribed.

3. There is need for pharmacists to counsel patients on common side effects that may be encountered, including how to avoid them and what to do when they occur.

4. Physicians should also consider the financial status of their patients in prescribing anti-diabetic medications to enable affordability.

\section{REFERENCES}

[1] Diabetes Control and Complications Trial Research Group. (1996). Influence of intensive diabetes treatment on quality of life outcomes in the Diabetes Control and Complications Trial. Diabetes Care, 19, 195-203.

[2] King H, Aubert R E., Herman W H; Global burden of diabetes 1995-2025: Prevalence, numerical estimates and projections. Diabetes Care; 21:1414-1431.

[3] World health organisation and the International Diabetes Federation: Regional Partners (1999). Bulletin of the World Health Organization; 77:954.

[4] Glasgow, R. E. McCaul, K. D., \& Schafer, L. C. (1987). Self-care behaviours and glycemic control in Type 1 diabetes. Journal of Chronic Diseases, 40, 399-412.

[5] American Diabetes Association (2000c). Standards of medial care for patients with diabetes mellitus (Position Statement). Diabetes Care, 23, S32-S42.

[6] Diabetes Control and Complications Trial Research Group. (1993). The effect of intensive treatment of diabetes on the development and progression of long-term complications in insulin-dependent diabetes. New England Journal of Medicine, 329, 977-986.

[7] World Health Organization (2003). Adherence to long-term therapies: Evidence for action. Geneva, Switzerland: Author.

[8] Cramer JA (2004). A systematic review of adherence with medications for diabetes. Diabetes Care; 27:1218 - 1224. [PubMed].

[9] Sokol MC, McGuigan KA, Verbrugge RR, Epstein RS(2005). Impact of medication adherence on hospitalization risk and healthcare cost Med Care; 43:521-530 [PubMed].

[10] Anderson DKG, Svardsudd K (1995): Long term glycemic control relates to mortality in type 2 diabetes. Diabetes Care. 1995; 18:1534-1543. Archives of Internal Medicine, 147, 1749-1753

[11] Jacques CHM, Jones RL(1993): Problems encountered by primary care physicians in the care of patients with diabetes. Arch Fam Med; 2:739-741.

[12] Lwang S, Lemeshow S(1991) Sample size determination in health studies: a practical manual. Geneva, world Health Organization 1991:24-255.

[13] Diabcare Nigeria study group (2012). Profile of Nigerians with diabetes mellitus. Indian J Endocrinol metab;16(14):558-564.

[14] Okoro RN, Ngong CK (2012). Assessment of patient's antihypertensive medication adherence level in a non-co-morbid hypertension in a tertiary hospital in Nigeria. Int J pharm Biomed Sci, 3(2) 47-54.

[15] Adisa R, Alutundu M B, Fakeye T O (2009); Factos contributing to non-adherence to oral hypoglycaemic medications among ambulatory type 2 diabetes patients in SouthWestern Nigeria. World journal of Pharmacy Practice; 7 (3): 163-169.

[16] Ebesunun MO, Adedipe O (2011). Glycated haemoglobin, lipids and drug adherence in Type 2 diabetes mellitus: experience in high income group. Journal of medicine and medical sciences vol. 2(1), pp 642647.

[17] Tiv M, Mauny F, Eschwe'ge E, Weil A (2012). Medication adherence in type 2 Diabetes: the ENTRED study 2007, a France population based study PLOS ONE; 7(3):32412

[18] Hill-Briggs F, Gary T. L., Bone L. R, Hill M N, Levine D M, Bancati F L(2005), Medication adherence and diabetes control in Urban African American with type 2 diabetes. Health Psychol; 24:349-357.

[19] Bailey, C.J., \& Turney, R.C. (1996). Metformin. New England Journal of Medicine, 334, 503-514. Association, 261, 3273-3277.

[20] Ponnusankar S, Surulivelrajan M, Anandamoorthy (2004). Assessment of impact of medication counseling on patients' medication knowledge and compliance in an outpatient clinic in South India. Patient Educ Couns; 54:55-60. 
[21] Gimenes H T, Zanetti M L, Haas V J (2009); Factors related to patient adherence to antidiabetic drug therapy. Rev Lat Am Enfermagem; 17(1): 46-51.

[22] Swett C Jr. Noones J(1989); Factors associated with premature termination from outpatient treatment. Hosp Community Psychiatry; 40:947-951

[23] Spikmans F J, Brug J, Doven M M(2003). Why do diabetic patients not attend appointments with their dietitian. J Hum Nutr Diet: : 16:151-158.

[24] Horne R, Weinman J (1999); Patients' beliefs about prescribed medicines and their role in adherence to treatment in chronic physical illness. J Psychosom Res. 1999; 47:555-567. 